\title{
Eco-friendly Dyeing of Mulberry Silk Yarn with Bark of Artocarpus lacucha
}

\author{
Gitanjali Boruah $^{1}$, Ava Rani Phukan ${ }^{1}$ and Shankar H. Gogoi ${ }^{*}$ \\ ${ }^{1}$ Department of Textiles and Apparel Design, ${ }^{2}$ Department of Plant Pathology, Assam \\ Agricultural University, Jorhat, Assam, 785013, India \\ *Corresponding author
}

\section{A B S T R A C T}

\begin{tabular}{|l|}
\hline K e y w o r d s \\
$\begin{array}{l}\text { Artocarpus lacucha, } \\
\text { Natural dyeing, Silk, } \\
\text { Mordants, Copper } \\
\text { sulphate }\end{array}$ \\
\hline Article Info \\
\hline $\begin{array}{l}\text { Accepted: } \\
\text { 06 August } 2018 \\
\text { Available Online: } \\
\text { 10 September } 2018\end{array}$ \\
\hline
\end{tabular}

\section{Introduction}

Dyeing is one of the most delightful textile arts which are an important branch in fashion design. Natural dye is a fascinating phenomenon that enticed researchers to their chemistry and production of fantastic novel hues to explore the point that no other dyes provide a better opportunity of teaching how to protect and respect the environment (Khadijah and Heba, 2013).

Each plant has specific dye components that determine its shade of color and fastness to light (Ellis, 2013).
For thousands of years human beings have used natural colours for a variety of purposes. With the advent of synthetic colorants, the use of natural colorants saw a drastic decline, the main reasons being that, with synthetic colorants, it was possible to obtain a wider range of colours and better colour fastness at a reasonable price.

However, in recent years there is an increasing demand for natural colorants because of the rising interest in preserving ecosystems, attributable to the fact that they are more quickly biodegraded than the synthetic dyes (Gowda et al., 2014). 


\section{Materials and Methods}

\section{Selection of natural dye}

Natural dyes make an important contribution to fabric decoration by producing various beautiful colours and colour harmonies obtained by a combination of varying dyeing methods.

Colouring matter was extracted from the root, stem, leaves, berries and flowers of the various types of plants.

The lakoocha (A. lakoocha Roxb) is also known as monkey jack or lakuchi in India, tampang and other similar native names in Malaya, as lokhat in Thailand. The tree is 20 to $30 \mathrm{ft}(6-9 \mathrm{~m})$ tall with deciduous, large, leathery leaves, downy on the underside. The fruits are nearly round or irregular, 2 to 5 in $(5-12.5 \mathrm{~cm})$ wide, velvety, dull-yellow tinged with pink, with sweet sour pulp which is occasionally eaten raw but mostly made into curries or chutney (Plate 1).

\section{Chemicals}

The chemicals used are sodium carbonate, hydrochloric acid, hydrogen peroxide, copper sulphate, stannous chloride and ferrous sulphate (All chemicals were procured from Fisher Scientific, India), sulphuric acid and ferric chloride hexahydrate LR were received from S. D. Fine Chemicals Limited (SDFCL) Mumbai, India. Zinc dust (A.W. 65.37) was received from RFCL Limited, Gujarat, India.

\section{Mordants}

Mordants used for the studies were copper sulphate, ferrous sulphate and stannous chloride. The amount of mordant to be used was calculated based on the weight of yarn expressed in terms of percentage as given in the following equation:
Amount of mordant $=$

Weight of the yarnin gram $\times \%$ of mordant

100

\section{Extraction of natural colorants}

The monkey jack bark was cleaned and dried. The dried dye sources were powdered and 1.0 $\mathrm{g}$ was extracted separately in water, alakline $\left(1.0 \%\right.$ of $\left.\mathrm{Na}_{2} \mathrm{CO}_{3}\right)$ acid $(1.0 \%$ of $\mathrm{HCl})$ medium. The extraction was performed at $100^{\circ} \mathrm{C}$ for 60 minutes, keeping 1:50 matrial to liqor ratio. The dye extracts were then subjected to colorimetric analysis and the optical density value was determined using an UV vis- Spectrophotometre.

\section{Pre-treatment of the silk yarn}

Degumming and bleaching methods were carried out for the study by using the procedure adopted by Gogoi (2004). Mulberry silk yarns were weighed accurately at M: L ratio of 1:50 and emerged into the water. Required quantity of washing soda (5 g/ litre) was added to water and started heating at $60^{\circ} \mathrm{C}$ temperature. After 30 minutes the yarns were taken out and washed properly in running water and then air dried. After degumming, the degummed yarns were bleached to improve the whiteness property of the yarn. Required quantity of water was taken and heated at temperature of $50^{\circ} \mathrm{C} .1 \%$ hydrogen peroxide was added to the liquor. Sodium silicate was added to the bleaching bath as a stabilizing agent in the middle of the process. Yarns were taken out after 30 minutes and washed properly in the running water and air dried.

\section{Determination of solid content of extracted dye solution}

The solid content of the dye extracts was determined by taking a measured extracts in a pre-weighted Petri dish and the contents were 
dried in an oven at $100 \pm 5^{\circ} \mathrm{C}$ till completely dried and the residue was obtained. The materials was kept in desiccators to cool down and then weighed. The solid content of the extracted dye solution was obtained as follows:

$\%$ of $\quad$ solid
$\frac{\mathrm{W}_{2}-\mathrm{W}_{1}}{\text { Weight of the solution }} \times 100$

Where,

$\mathrm{W}_{1}=$ weight of the Petri dish

$\mathrm{W}_{2}=$ weight of the Petri dish + solid

$1 \%$ of solid dye content was obtained from 3 $\%$ of extracted dye solution.

\section{Optimization of mordanting methods}

In Pre-mordanting method, an aqueous solution was prepared by dissolving required amount of mordant in water. The yarns were boiled in $70^{\circ} \mathrm{C}$ in this solution for 30 minutes and then immerged in the prepared dye solution for dyeing. In simultaneous method, the mordants and dye were applied simultaneously in the same bath. The mulberry silk yarns were placed in the extracted dye bath and dyed for 15 minutes. After that, the required amount of mordants were added to the dye solution by lifting yarns and mixed properly.

The yarns were then dyed in the solution for 30 minutes. In post mordanting method, the samples were first dyed with dye solution and then mordanted. A mordanting bath was prepared as per recipe for mordanting. After dyeing, the samples were removed with the help of glass rod and then entered in the mordanting bath and heated to a temperature of $60-70^{\circ} \mathrm{C}$ for 30 minutes. Then the samples were allowed to cool, rinsed and dried in shade.

\section{Colour measurement}

\section{Determination of colour co-ordinates}

The CIE Lab colour co-ordinate value of all the dyed samples were recorded as average of five times readings in Brightness, Opacity and Colour Tester (Model no UEC-1080).

The colour parameters $\mathrm{L}^{*}$ (depth of colour), $\mathrm{a}^{*}$ (positive value redness and negative greenness) and $b^{*}$ (positive value yellowness and negative value blueness) were recorded.

The said values were ascertained for all mordants used in study. The lower value $\mathrm{L}^{*}$ value indicated greater depth of colour and higher value of $\mathrm{a}^{*}$ and $\mathrm{b}^{*}$ indicated brightness of colour. The reflectance values were determined using following Kubelka -Munk equation:

$$
\frac{\mathrm{K}}{\mathrm{S}}=\frac{(1-\mathrm{R})^{2}}{2 \mathrm{R}}
$$

Where $\mathrm{K}$ is the absorption coefficient, $\mathrm{S}$ is the scattering coefficient, and $\mathrm{R}$ is the reflectance of the dyed fabric at the wavelength of maximum absorption.

\section{Determination of fastness properties of dyed sample}

The colour fastness property of yarn is depends on various factors like chemical structure of dye, yarn type, dyeing time, and temperature used on dyeing (Mahale et al., 2003).

All the dyed samples of mulberry silk yarn were evaluated for colour fastness to washing, colour fastness to sunlight, colour fastness to crocking (dry and wet), colour fastness to pressing (dry and wet) and colour fastness to perspiration (acidic and alkaline) by using ASTM procedure. 


\section{Results and Discussion}

\section{Determination of wavelength for selected dye}

It was observed that the absorbance pattern of monkey jack dye showed the highest absorbance of $460 \mathrm{~nm}$ (bluish-green colour) as optimum (Table 1). Gohl and Vilensky (1983) expressed that wavelength range for bluishgreen was 460-500 nm.

\section{Optimization of dye extraction medium}

For optimization of dye extraction medium, dye of powders were extracted separately in plain water, in alkaline medium $(1 \%$ of $\left.\mathrm{Na}_{2} \mathrm{CO}_{3}\right)$ and in acidic medium $(1 \%$ of $\mathrm{HCl})$ with material to liquor ratio $1: 50$, at $100^{\circ} \mathrm{C}$ for 60 minutes duration (Table 2). It was evident from the Table 2 that the optical density of extracted monkey jack dye solution in alkaline medium was found maximum (0.900) than in aqueous (0.607) and acidic (0.595). Phukan et al., (2014) also found similar result on silk yarns dyed with Morinda angustifolia.

\section{Optimization of alkali $\left(\mathrm{Na}_{2} \mathrm{CO}_{3}\right)$ concentration for extraction of dye}

The concentration of alkali $\left(\mathrm{Na}_{2} \mathrm{CO}_{3}\right)$ for extraction of dye was optimized by extracting monkey jack in different concentration of alkali viz., $0.1 \mathrm{~g}$ to 1.0 grams with material to liquor ratio 1:50 for 60 minute duration at $100^{\circ} \mathrm{C}$ (Fig. 1). In monkey jack dye maximum optical density value $(0.413)$ obtained at 0.7 per cent concentration of alkali. Hence, $0.7 \%$ concentration of alkali for dye was considered as optimized alkali concentration.

\section{Optimization of dye extraction time}

The extraction times for dyes were optimized based on highest optical density values. Dyes were extracted in $\mathrm{M}$ : L ratio $1: 50$ at $100^{\circ} \mathrm{C}$ for different time period viz., 30, 45, 60, 75 and
90 minutes duration. The optical densities recorded for different time period presented in Table 3. Maximum optical density value (0.631) was obtained from 60 minutes and decreasing trend in optical density values obtained after 60 minutes. It may be due to the saturation of dye molecule. Similar result has been found by Pandey et al., (2014) on silk dyeing with binary mixture of Ficus religiosa and Moringa pteygosperma leaves.

\section{Optimization of dye material concentration}

The concentrations of dyes were optimized by dyeing mulberry silk yarns in different concentration of dye viz. 1 to $10 / 100 \mathrm{gm}$ of yarn. The absorption (\%) of dye by the yarns were calculated based on optical densities of the dye liquor before and after dyeing were presented in Figure 2. It was clear from the Figure 2. That, in monkey jack dye maximum absorption $(39.60 \%)$ was found at 9 per cent concentration of dye and minimum $(21.89 \%)$ was observed in 1 per cent concentration of dye.

\section{Optimization of dyeing time}

For dyeing mulberry silk yarn with monkey jack dyes, the dyeing time was optimized based on (\%) absorption of dye. For this purpose dyeing was carried out for different time period viz. 30, 45, 60, 75 and 90 minutes duration and optical densities of the dye liquor before and after dyeing was recorded. From the recorded optical density values, absorption (\%) of the dye by the yarns were calculated and presented in Table 4 . The per cent dye absorption increased with the increase in dyeing time and reached its maximum at 45 minute (36.09) and then decreased. It might be due to optimum saturation of dye molecule. Hence, the optimum dyeing time was selected as $45 \mathrm{~min}$ for dyeing silk yarn. Similar observations were made by Singh (2000) and Duarah (2007) in the case of Berberry and Telanthera ficoidea dye. 
Table.1 Absorbance pattern of monkey jack

\begin{tabular}{|c|}
\hline Sl. No \\
\hline 1. \\
\hline 2. \\
\hline 3. \\
\hline 4. \\
\hline 5. \\
\hline 6. \\
\hline 7. \\
\hline 8. \\
\hline 9. \\
\hline 10.
\end{tabular}

\begin{tabular}{|c|c|}
\hline Wavelength & OD value \\
\hline 400 & 1.144 \\
\hline 410 & 1.164 \\
\hline 420 & 1.211 \\
\hline 430 & 1.235 \\
\hline 440 & 1.314 \\
\hline 450 & 1.329 \\
\hline 460 & 1.336 \\
\hline 470 & 1.321 \\
\hline 480 & 1.305 \\
\hline 490 & 1.295 \\
\hline
\end{tabular}

Table.2 Optimization of dye extraction medium

\begin{tabular}{|c|c|c|c|c|}
\hline S1. No. & Extraction medium & Time (min.) & Temperature $\left({ }^{\circ} \mathbf{C}\right)$ & O.D value \\
\hline 1. & Aqueous & 60 & 100 & 0.607 \\
\hline 2. & Alkaline & 60 & 100 & 0.900 \\
\hline 3. & Acidic & 60 & 100 & 0.595 \\
\hline
\end{tabular}

Table.3 Optimization of dye extraction time

\begin{tabular}{|c|c|c|c|}
\hline SI. No. & $\begin{array}{c}\text { Extraction time } \\
(\mathbf{m i n} .)\end{array}$ & $\begin{array}{c}\text { Temperature } \\
\left({ }^{\circ} \mathbf{C}\right)\end{array}$ & Dye absorption (\%) \\
\hline 1. & 30 & 100 & 0.566 \\
\hline 2. & 45 & 100 & 0.584 \\
\hline 3. & 60 & 100 & 0.631 \\
\hline 4. & 75 & 100 & 0.603 \\
\hline 5. & 90 & 100 & 0.579 \\
\hline
\end{tabular}

Table.4 Optimization of dyeing time

\begin{tabular}{|c|}
\hline Sl. No. \\
\hline 1. \\
\hline 2. \\
\hline 3. \\
\hline 4. \\
\hline 5. \\
\hline
\end{tabular}

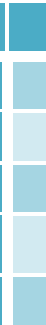

\section{Dyeing time (min.)}

30

45

60

75

90

\section{Temperature $\left({ }^{\circ} \mathrm{C}\right)$}

Dye absorption (\%)

70
70
70
70
70

33.65

36.09

34.47

33.82

30.19 
Table.5 Optimization of mordant concentration

\begin{tabular}{|l|c|c|}
\hline Name of the mordant & $\begin{array}{c}\text { Mordant concentration } \\
\text { (g/100gm of yarn) }\end{array}$ & Dye absorption (\%) \\
\hline Copper sulphate & 1 & 45.43 \\
\hline 2 & 43.69 \\
\hline Ferrous sulphate & 3 & 40.78 \\
\hline & 5 & 36.98 \\
\hline & 1 & 34.43 \\
\hline 2 & 30.87 \\
\hline Stannous chloride & 3 & 34.54 \\
\hline 4 & 35.98 \\
\hline 5 & 38.04 \\
\hline 1 & 36.98 \\
\hline 2 & 47.21 \\
\hline & 3 & 45.27 \\
\hline 4 & 40.47 \\
\hline
\end{tabular}

Table.6 Optimization of mordanting time

\begin{tabular}{|c|c|c|}
\hline Name of the mordant & Mordanting time (min.) & Dye absorption (\%) \\
\hline \multirow{2}{*}{ Copper sulphate } & 15 & 41.54 \\
\hline & 30 & 42.11 \\
\hline \multirow{3}{*}{ Ferrous sulphate } & 45 & 38.30 \\
\hline & 60 & 34.18 \\
\hline & 75 & 33.22 \\
\hline & 15 & 32.07 \\
\hline Stannous chloride & 30 & 37.84 \\
\hline & 45 & 35.87 \\
\hline 60 & 34.21 \\
\hline 75 & 31.63 \\
\hline & 15 & 37.25 \\
\hline & 30 & 40.81 \\
\hline & 45 & 38.73 \\
\hline
\end{tabular}


Table.7 Optimization of mordanting method

\begin{tabular}{|c|c|c|}
\hline Name of the mordant & $\begin{array}{c}\text { Mordant concentration } \\
\text { (g/100gm of yarn) }\end{array}$ & Dye absorption (\%) \\
\hline \multirow{3}{*}{ Copper sulphate } & 1 & 45.43 \\
\hline & 2 & 43.69 \\
\hline \multirow{3}{*}{ Ferrous sulphate } & 3 & 40.78 \\
\hline & 4 & 36.98 \\
\hline & 5 & 34.43 \\
\hline & 1 & 30.87 \\
\hline \multirow{3}{*}{ Stannous chloride } & 2 & 34.54 \\
\hline & 3 & 35.98 \\
\hline & 4 & 38.04 \\
\hline & 5 & 36.98 \\
\hline & 1 & 47.21 \\
\hline & 2 & 45.27 \\
\hline
\end{tabular}

Table.8 Computer colour matching data

\begin{tabular}{|c|c|c|c|c|c|c|c|}
\hline Sl. No & Details & L* & $\mathbf{a}^{*}$ & $\mathbf{b} *$ & $\mathbf{C}$ & $\mathbf{H}$ & K/S \\
\hline $\mathbf{1}$ & Monkey jack dye & 53.52 & 10.58 & 14.04 & 17.58 & 52.97 & 0.89 \\
\hline $\mathbf{2}$ & Monkey jack with Copper sulphate & 52.80 & 8.32 & 12.22 & 14.78 & 55.71 & 3.00 \\
\hline 3 & Monkey jack with ferrous sulphate & 50.70 & 5.98 & 10.58 & 12.15 & 60.49 & 1.47 \\
\hline 4 & Monkey jack with Stannous chloride & 54.27 & 10.52 & 14.26 & 17.72 & 53.55 & 1.41 \\
\hline
\end{tabular}

Table.9 Ratings for colourfastness properties of Monkey jack dyed samples

\begin{tabular}{|c|c|c|c|c|c|c|c|c|c|c|c|c|c|c|c|c|}
\hline \multirow{3}{*}{$\begin{array}{l}\text { Sl. } \\
\text { No. }\end{array}$} & \multirow{3}{*}{$\begin{array}{l}\text { Mordants } \\
\text { used }\end{array}$} & \multirow[t]{3}{*}{ Sunlight } & \multirow{2}{*}{\multicolumn{2}{|c|}{ Washing }} & \multicolumn{4}{|c|}{ Crocking } & \multicolumn{4}{|c|}{ Perspiration } & \multicolumn{4}{|c|}{ Pressing } \\
\hline & & & & & \multicolumn{2}{|c|}{ Dry } & \multicolumn{2}{|c|}{ Wet } & \multicolumn{2}{|c|}{ Acidic } & \multicolumn{2}{|c|}{ Alkaline } & \multicolumn{2}{|c|}{ Dry } & \multicolumn{2}{|c|}{ Wet } \\
\hline & & & $\mathrm{CC}$ & CS & $\mathrm{CC}$ & CS & $\mathrm{CC}$ & CS & $\mathrm{CC}$ & CS & $\mathrm{CC}$ & CS & $\mathrm{CC}$ & CS & $\mathrm{CC}$ & CS \\
\hline 1. & $\begin{array}{l}\text { Without } \\
\text { mordant }\end{array}$ & 3 & 5 & 5 & 5 & 5 & 5 & 5 & 4 & 5 & 5 & 4 & 4 & 4 & 5 & 4 \\
\hline 2. & $\begin{array}{l}\text { Copper } \\
\text { sulphate }\end{array}$ & 4 & 4 & 5 & 5 & 5 & 4 & 4 & 5 & 5 & 4 & 5 & 5 & 5 & 4 & 4 \\
\hline 3. & $\begin{array}{l}\text { Ferrous } \\
\text { sulphate }\end{array}$ & 3 & 4 & 5 & 5 & 5 & 4 & 4 & 4 & 5 & 4 & 4 & 5 & 4 & 5 & 5 \\
\hline 4. & $\begin{array}{l}\text { Stannous } \\
\text { chloride }\end{array}$ & 3 & 5 & 5 & 5 & 5 & 4 & 5 & 5 & 5 & 5 & 5 & 5 & 5 & 5 & 5 \\
\hline
\end{tabular}


Plate.1 a) Dried Monkey jack bark \& b) Monkey jack plant
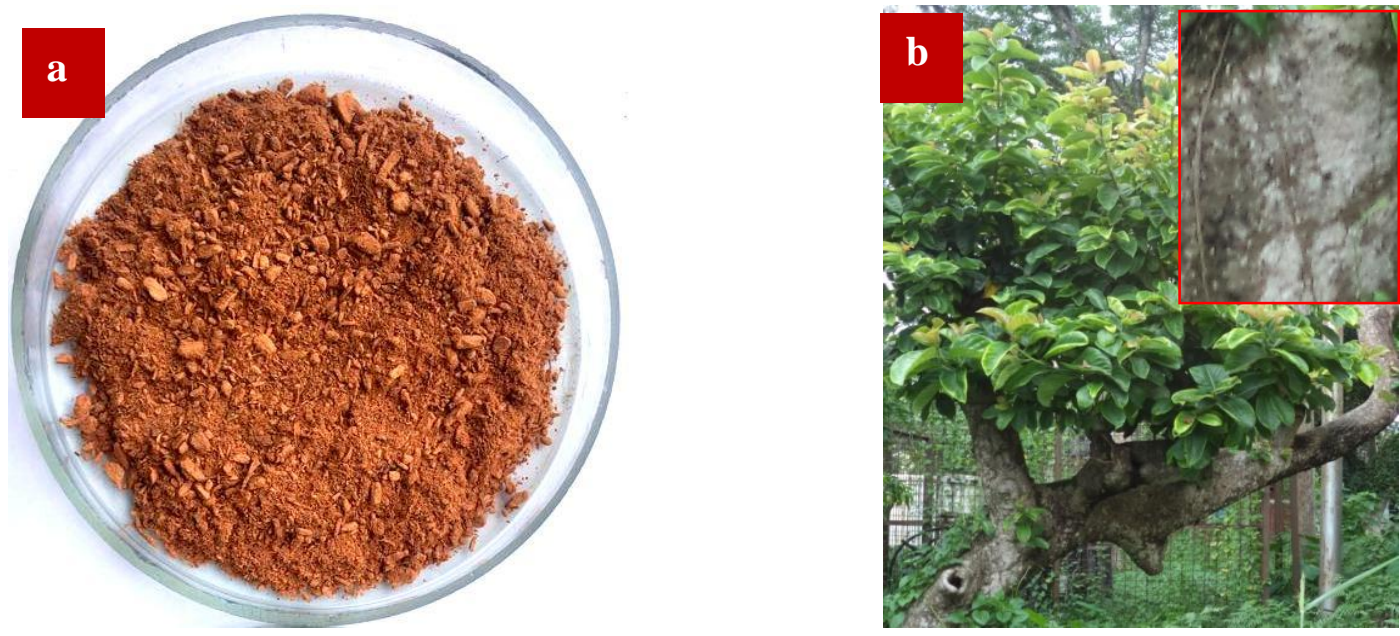

Plate.2 Colour produced by dyes on mulberry silk
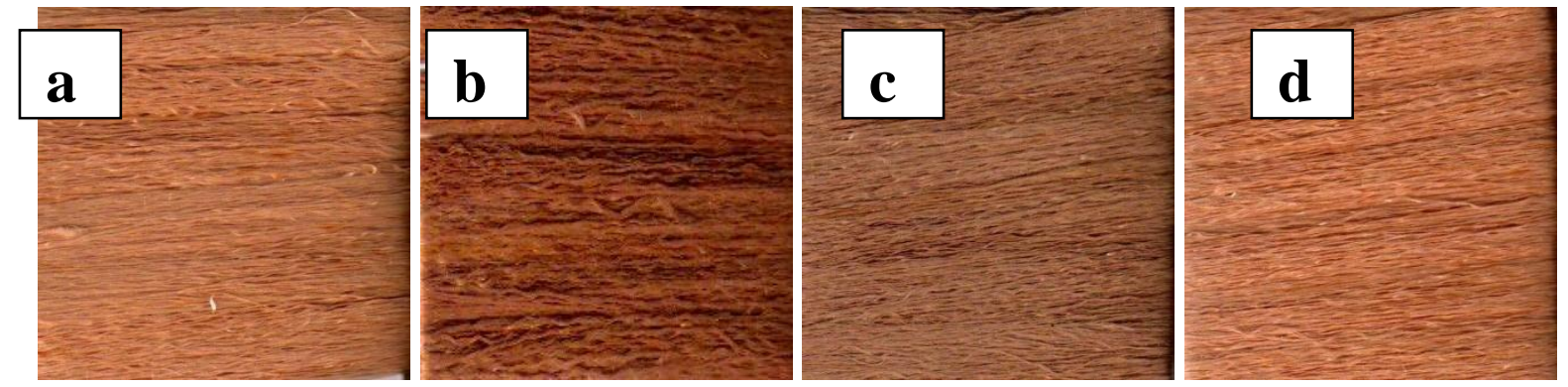

a) Monkey jack

b) Monkey jack with Copper sulphate

c) Monkey jack with Ferrous sulphate

d) Monkey jack with Stannous chloride

Fig.1 Optimization of alkali $\left(\mathrm{Na}_{2} \mathrm{CO}_{3}\right)$ concentration for extraction

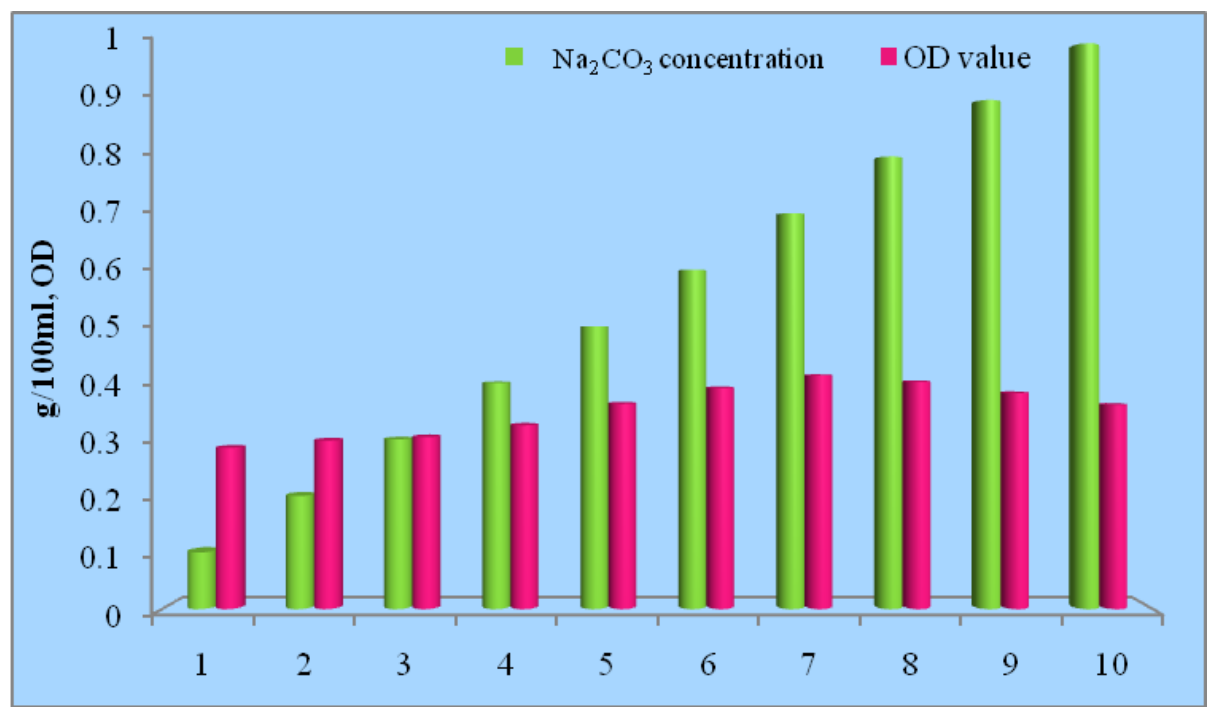


Fig.2 Optimization of dye material concentration

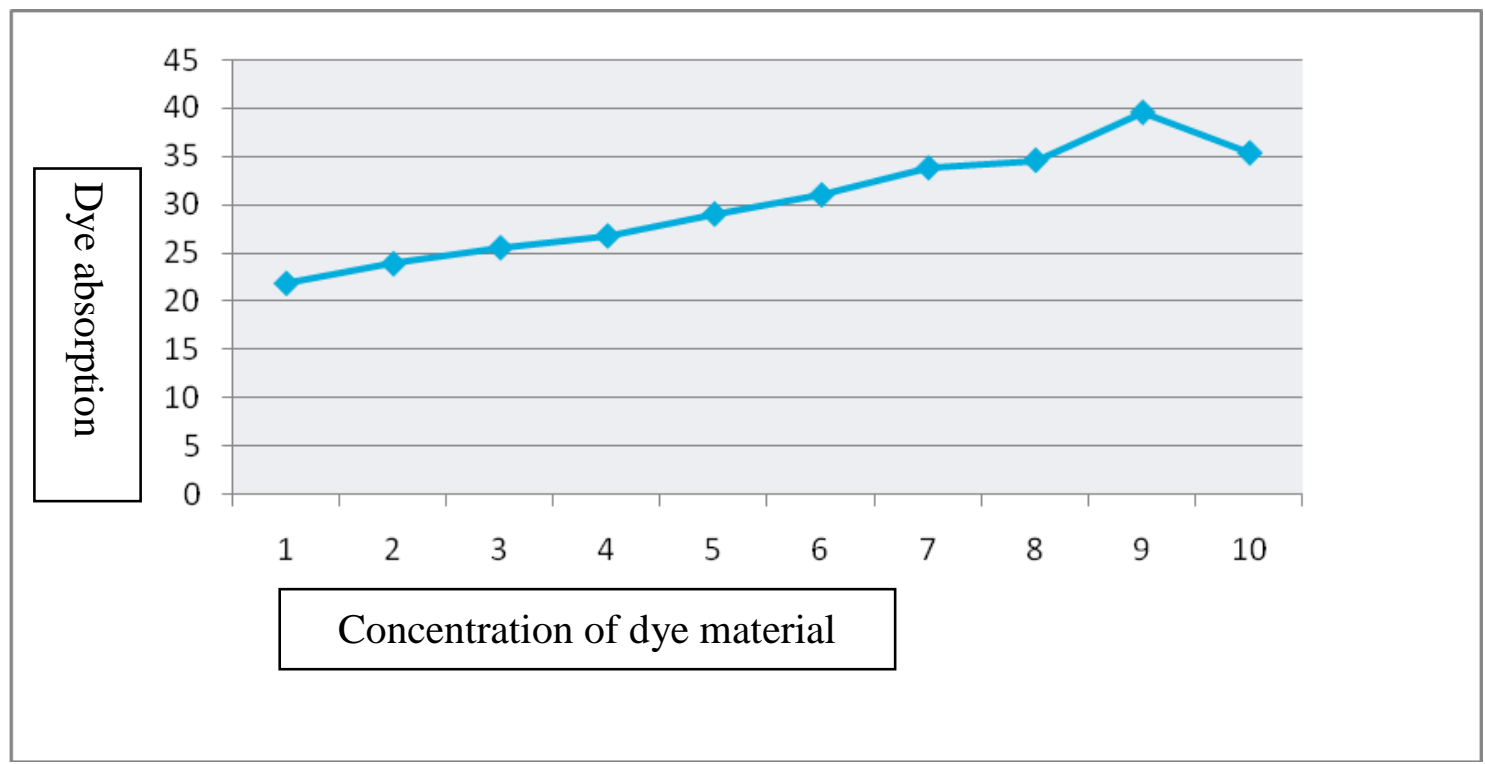

\section{Optimization of mordant concentration}

The concentration of $\mathrm{CuSO}_{4}$ mordant showed maximum absorption $(45.43 \%)$ at 1 per cent concentration. But as the concentration was increased the absorption (\%) was decreased gradually and it was observed that concentration of $\mathrm{FeSO}_{4}$ showed the highest absorption $(38.04 \%)$ at 4 per cent concentration in monkey jack. The concentration of $\mathrm{SnCl}_{2}$ showed maximum absorption (47.21\%) at 1 per cent concentration for monkey jack.

\section{Optimization of mordanting time}

After optimization of mordant concentration, mordanting time for each mordant was optimized by dyeing mulberry silk yarns with optimized concentration of mordant for different time period viz. 15, 30, 45, 60 and 75 minutes in simultaneous mordanting method (Table 6).

From the results it could be concluded that 30 minutes duration of mordanting time was considered as suitable mordanting time for each mordant. Similar result has been shown by Pandey et al., (2014) on silk dyeing with binary mixture of Ficus religiosa and Moringa pterygosperma leaves.

\section{Optimization of mordanting method for all the mordants}

From the Table 7, it could be concluded that simultaneous mordanting method was considered as suitable mordanting method for each mordant. Similar observation has been obtained by Kumersan (2014).

\section{Colour measurement}

Table 8 shows $L^{*}, a^{*}, b^{*}$ values for dyed samples. Tests were done with the help of Brightness Opacity and colour Tester, UEC1018. The monkey jack dye shows maximum $\mathrm{a}^{*}$ values (10.58). When the dye is mixed with metallic mordants, the redness got decreased. Chroma value shows the colour intensity. The silk yarn dyed with monkey jack in combination of stannous chloride mordant shows highest $C$ value (17.72). The ferrous sulphate mordanted treated dye produced highest hue value (60.49). The total colour value of the dyed material is expressed 
in terms of K/S. The least K/S value (0.89) was observed when the silk yarn is dyed with monkey jack dye. There is significant change in the K/S value of the shades dyed either with monkey jack alone or with mordent combination. The total colour value of the monkey jack dye got enhanced in combination with metallic mordants. The addition of mordant increased the K/S value. However, marginal change in the tone of shade was observed with various mordents.

\section{Colour produced by dyes on mulberry silk}

Different shades of colour produced after dyeing of mulberry silk yarn with the bark of monkey jack dye were shades of brown and shades of beige (Plate 2).

\section{Evaluation of colour fastness properties}

After dyeing in optimum dyeing conditions using different mordants the mulberry yarns were evaluated for their fastness properties like colour fastness to sunlight, colour fastness to washing, colour fastness to crocking (dry and wet), colour fastness to pressing (dry and wet) and colour fastness to perspiration (acidic and alkaline) by using International Grey Scale and compared with the controlled sample (Table 9).

From the table it is observed that, when monkey jack dyes were mordanted with copper sulphate showed very fair (4) colour fastness to sunlight. While ferrous sulphate, stannous chloride and without mordant showed moderate (3) colour fastness to sunlight. All mordanted dyed samples showed in the range of very fair to good fastness properties. In case of rubbing, all dyed samples showed good (5) colour fastness in dry condition. In perspiration, copper sulphate and stannous chloride mordanted sample exhibited good(5) colour fastness in acidic condition, however, the ferrous sulphate mordented samples showed comparatively lesser fastness. Ferrous sulphate and stannous chloride mordanted dyed sample showed good (5) and negligible (5) fastness properties in pressing. The overall colour fastness properties of sunlight, washing, rubbing (dry and wet), perspiration (acidic and alkaline) and pressing (dry and wet) were found to be good and satisfactory.

Sheth (2005) reported that light fastness of dye is not only influenced by chemical constituents of dye but also several other factors such as physical state of dye in the substrate, types of bond between dye and fibre, nature of substrate, source of radiation and its intensity, temperature, humidity condition, presence of foreign substance, atmospheric contaminants and after treatments given to dyed yarns/ fabrics for improving performance characteristics.

Colouring of mulberry yarns with different dyestuffs enhances the fibre as well as aesthetic value. In present study it has been found that the, alkaline medium was the most suitable method for dye extraction. The colour intensity of the treated yarns was varied due to using of different mordants. Silk yarn dyed with monkey jack in combination of stannous chloride mordant shows highest $\mathrm{C}$ value (17.72). The ferrous sulphate mordant along with monkey jack produced highest hue value (60.49). The total colour value of the dyed material is expressed in terms of K/S.

There is significant change in the K/S value of the shades dyed either with monkey jack alone or with mordant combination. The total colour value of the monkey jack dye got enhanced in combination with metallic mordants. The addition of mordant increased the K/S value. However, marginal change in the tone of shade was observed with various mordents. The overall colour fastness properties of sunlight, washing, rubbing (dry 
and wet), perspiration (acidic and alkaline) and pressing (dry and wet) were found to be good and satisfactory.

\section{References}

Duarah, P. (2006). Dyeing of mulberry silk with Telanthera ficoidea dye. M.Sc. (H.Sc.) Thesis, AAU, Jorhat.

Ellis, C. (2013). The science of natural dyes. Surface Design Journal, p. 26.

Gogoi, N. (2004). Studies on bleaching and dyeing behaviour of eri (Philosomia ricini) silk and evaluation of its physiochemical properties. Ph.D (H.Sc.) Thesis, Assam Agricultural University, Jorhat.

Gowda, K.N.N.; Smitha, R.S. and Sudhakar, R. (2014). Cannon ball flower, a new source of natural dye for silk. International workshop on Natural Dyes, p. 76.

Khadijah, Q. and Heba, M. (2013). Environmental production of fashion colors from natural dyes. Int. J. Physic. Sci., p. 670.
Kumaresan, M. (2014). Fastness Properties of Dyed Silk Fabric with Eco-Friendly Natural dyes obtained from Achras sapota and Cordia sebestena - A comparison. J. Environ. Nanotechnol. 3(2): 194-199.

Mahale, G.S. and Sudanda, R.S. (2003). Silk dyed with Aclypha wilkeesiana and its fastness. Indian J. Fibre Text. 28(3): 8689.

Pandey, R., Bhargava, A. and Singh, S. (2014). Silk dyeing with binary mixture of Ficus religiosa and Moringa pterygosperma leaves. International Workshop on natural dyes. A.P. India, pp. 145-151.

Phukan, R.A. and Phukan, R. (2014). Fastness properties of silk yarns dyed with Morinda angustifolia with different mordant combinations. International Workshop on Natural Dyes, pp. 191199.

Sheth, G. (2005). Improvements in light fastness of reactive dyed fabric. Colourage, Pp. 100.

Singh, O.P. (2000). Natural dyes: the pros and cons. Indian Tex. J., pp. 42-46.

\section{How to cite this article:}

Gitanjali Boruah, Ava Rani Phukan and Shankar H. Gogoi. 2018. Eco-friendly Dyeing of Mulberry Silk Yarn with Bark of Artocarpus lacucha. Int.J.Curr.Microbiol.App.Sci. 7(09): 552-562. doi: https://doi.org/10.20546/ijcmas.2018.709.066 